\title{
Covid-19 and diabesity: when a pandemia cross another pandemia
}

\author{
Gloria Guarisco $^{1}\left[\right.$ Frida Leonetti $^{1}$
}

Received: 27 May 2020 / Accepted: 7 July 2020 / Published online: 14 July 2020

(c) Springer Nature Switzerland AG 2020

\begin{abstract}
The Covid-19 epidemic is having a strong impact on the population with pre-existing chronic diseases. The collision between the Covid-19 pandemic and the current diabesity epidemic has highlighted that obese and diabetic patients have a worse prognosis due to the impairment of the immune response to infections and due to the mechanical limits that make the management of the hospitalized patients with severe obesity more difficult. The limitations imposed on accessibility to non-urgent care during the lockdown of "phase 1" of this pandemic have created the need to revolutionize clinical practice to meet the health demands of chronic and high-risk diseases such as obesity and diabetes. The use of technology and risk stratification to establish the priority of access to the treatments that we have been forced to undertake will be useful tools for a new phase of a more efficient and successful treatment of diabesity.
\end{abstract}

Coronavirus disease-2019 (COVID-19), caused by the new corona virus SARS-CoV-2, is a pandemic that originated in China in December 2019, spread worldwide in a few months. As May 14, 2020, there are over 4 million cases of contagion worldwide and over 290.000 deaths. The United States rank first with over 1 million infections and over 84.000 deaths. Italy is in third place for deaths (over 31.000) and in fifth place, after Spain, for infections (over 220.000) [1].

"Diabesity" was considered the pandemic of the 3rd millennium until Covid-19 outbreak. The term underlines the intricate relationship between obesity and type 2 diabetes (T2DM). Most patients with T2DM are affected by obesity and the global rise in obesity largely explains the epidemic rise in incidence and prevalence of T2DM over the last few decades [2].

The use of the term "diabesity" and the attempt to consider obesity and diabetes as a single disease and not as two separate entities seems to be particularly important in the context of the COVID-19 pandemic.

The "Diabesity" epidemic is likely to be the biggest epidemic in human history up to February 2020 when WHO declared Covid-19 pandemic [3].

Gloria Guarisco

gloriaguarisco@gmail.com

1 Diabetes Unit, Department of Medical-Surgical Sciences and Biotechnologies, Santa Maria Goretti Hospital, Sapienza University of Rome, Via Guido Reni 1, 04100 Latina, Italy
The Covid-19 outbreak clinical picture is variable: the more severe cases are characterized by the development of a severe acute respiratory syndrome caused by extensive pulmonary fibrosis which is responsible for the high mortality in Italy (31.106 total deaths as May 14). In 31.5\% of the reported cases at least one co-morbidity is reported (cardiovascular, respiratory, diabetes, immune deficiencies, metabolic, oncological, obesity, renal or other chronic disorders) [4].

Data from the Intensive Care National Audit \& Research Centre (ICNARC) report on COVID-19 in critical care of United Kingdom (March 27th 2020) described that 72.1\% of 775 patients with confirmed COVID-19 were overweight or obese and that among patients with Body Mass Index $(\mathrm{BMI})>30 \mathrm{~kg} / \mathrm{m}^{2}$ who had undergone intensive care, $60.9 \%$ of them died.

Extensive Chinese observational reports on confirmed Covid-19 cases indicated that among patients with the most severe form of disease the prevalence of diabetes was $12-16 \%$ [5-8].

In Italy, as regards COVID-19 pandemic, the data reported by the ISS (Istituto Superiore di Sanità), updated to 7 May, obtained from 2621 death, report that obesity was present in $11 \%$ of cases and diabetes in $31.1 \%$ of cases [4].

As regards our experience at the S.M. Goretti Hospital in Latina, from 6 March to 14 April 2020, among 89 hospitalized patients with an average age of 58 years ( $55.1 \%$ male), $18 \%$ had a BMI $\geq 30 \mathrm{~kg} / \mathrm{m}^{2}, 10.1 \%$ had a known diabetes and $20 \%$ (known and newly diagnosed diabetics) required insulin 
therapy for glycemic rise secondary to steroid treatment. Moreover, $5.6 \%$ of our patients was affected by diabesity and almost $28 \%$ of patients with diabetes was affected by obesity, but the data are continuously updated.

Based on literature data, diabetes may not increase the risk of SARS-CoV-2 infection but can worsen the outcome [9]. In patients with obesity and diabetes, the expression of ACE2, the functional receptor for SARS-CoV, is upregulated in adipocytes and turns adipose tissue into a potential target and viral reservoir. This may explain why obesity and diabetes are potential empowering factors for COVID-19 infection [10].

A summary report from the Chinese Center for Disease Control of 72,314 cases across the country showed a higher mortality rate in people with diabetes, compared to nondiabetics, which further proves that diabetes is a risk factor for the prognosis of COVID-19 [11].

Moreover, obesity is an independent risk for hypoventilation syndrome in Intensive Care Unit (ICU) patients [12] and so could contribute to respiratory failure in patients with acute respiratory distress syndrome (ARDS) [13].

In a French study, the risk for invasive mechanical ventilation in patients with COVID-19 infection admitted to Intensive Treatment Unit was more than sevenfold higher for those with BMI $>35$ compared with $\mathrm{BMI}<25 \mathrm{~kg} / \mathrm{m}^{2}$ [14]. Among individuals with COVID-19 aged less than 60 years in New York City, those with a BMI between $30-34 \mathrm{~kg} / \mathrm{m}^{2}$ and $>35 \mathrm{~kg} / \mathrm{m}^{2}$ were 1.8 times and 3.6 times more likely to be admitted to critical care, respectively, than individuals with a $\mathrm{BMI}<30 \mathrm{~kg} / \mathrm{m}^{2}[15]$.

In addition to the evident difficulty of treatment for patients with extreme obesity (e.g., BMI $>40 \mathrm{Kg} / \mathrm{m}^{2}$ ), due to difficult intubation, extubation, insertion of central IV-line, appearance of pressure ulcers, size limitations of diagnostic capabilities (MRI), lack of extralarge beds to accommodate this patients in medical units/ICUs, Sattar et al. from University of Glasgow speculated that one of the pathways by which obesity (and/or excess ectopic fat) may increase the severity of COVID-19 infection is the amplified or dysregulated immune response typical of the patient with obesity, that could mediate the progression to critical illness and organ failure [16].

It should be also emphasized that in patients with obesity the response to antiviral and antimicrobials drugs is poorer, the response to vaccine is reduced [17] and the adaptive immune responses to influenza virus is impaired [18] such as in patients with diabetes [19].

Therapies taken by patients with diabetes could also have an impact on Covid-19 infection, in fact insulin administration attenuates ACE2 expression [20, 21], while glucagonlike peptide-1 (GLP-1) agonists (liraglutide) and thiazolidinediones (pioglitazone), antihypertensives such as ACE inhibitors, and statins upregulate ACE2 [22-24].
In consideration of clinical experience and literature data, the presence of diabesity can be a further alarm in the management of Covid patient which should guide clinicians in the timing of the start of drug therapy and hospitalization.

On the other hand, the limitations imposed on accessibility to non-urgent care during the lockdown (phase 1) have postponed the outpatients' clinic access, favoring the progressive severity of diabesity-related co-morbidities. This scenario has required the use of new strategies for taking care of the patient by the health professionals responsible for the diabesity care: dietary or pharmacological interventions for weight control, telematic platforms of psychological supports, optimization of glycemic control through hypoglycemic therapies. If access to non-urgent care is more facilitated during phase 2 , the limitations, especially for fragile patients with diabesity, persist and therefore it may be essential to maintain alternate telematic consultancy strategies establishing priority criteria for access lists. The metabolic surgery, also, was stopped worldwide limiting the access to an effective treatment and limiting the armamentarium against diabesity [23, 25-27].

About that the DSS (Diabetes Surgery Summit) suggests criteria to help prioritize bariatric and metabolic surgery for when elective surgery is resumed, defining categories of access to surgery based on duration of diabetes, glycemic control, history of cardiovascular disease, presence of chronic kidney disease, non-alcoholic steatohepatitis and obesity-associated symptoms [28].

In our University Diabetes Unit, procedures for remote outpatient check-ups scheduled for over 12,000 patients with diabetes in charge were implemented, in accordance with the organizational proposals of the Italian Diabetes Society [29]. We have adopted strategies ranging from telephone contact to the consultation of the reports recorded and saved in clouds by patients using the CGM (continuous glucose monitoring) up to the use of an App(MySugr) that transmits blood sugar levels directly to our computerized medical record (Smart Digital Clinic) and which is able to automatically make a triage of the urgency of the doctor's intervention in the list of patients requesting an online visit. Over 500 virtual consultations have been performed: patients with a previously scheduled visit have been invited to send blood tests via email to our center and have been contacted by phone to confirm or modify the therapy. The medical staff consulted about a hundred digital glycemic records, communicating extemporaneously with the patient to provide indications for improving glycemic control. Our center was open for over $8 \mathrm{~h}$ a day for women with gestational diabetes and for all patients with "urgent" reservations to ensure access to the most complicated cases, assisting more than 100 patients with high priority. The nurses of our Unit carried out bureaucratic tasks such as renewing treatment plans for patients with diabetes. 
The fight against diabesity is not only fundamental in preventing the risks to which subjects with diabesity are normally exposed, but in this particular historical moment it is vital for better management of patients infected by SARSCoV-2, and for limiting the risk of mortality of the patients themselves, both to help reduce the rate of hospitalizations and lighten the burden on the health system caused by this vulnerable population subgroup.

Funding No funding was received for this work.

\section{Compliance with ethical standards}

Conflict of interest The authors declare that they have no conflicts of interest.

Ethical approval This article does not contain any studies with human participants or animals performed by any of the authors.

Informed consent For this type of article (Editorial), informed consent is not required because it does not contain any studies with human participants performed by any of the authors.

\section{References}

1. OMS https://www.who.int/emergencies/diseases/novel-coron avirus-2019/situation-reports. Accessed 2019

2. Chawla R, Jaggi S (2019) Medical management of diabesity. J Assoc Physicians India 67(12):52-56

3. Zimmet PZ (2017) Diabetes and its drivers: the largest epidemic in human history? Clin Diabetes Endocrinol. https://doi. org/10.1186/s40842-016-0039-3

4. https://www.epicentro.iss.it/coronavirus/. Accessed 2020

5. Yang X et al (2020) Clinical course and outcomes of critically ill patients with SARS-CoV-2pneumoniainWuhan, China: a single-centered, retrospective, observational study. Lancet Respir Med. https://doi.org/10.1016/S2213-2600(20)30079-5Feb24

6. Guan W, Ni Z, Hu Y et al (2019) Clinical characteristics of coronavirus disease 2019 in China. N Engl J Med. https://doi. org/10.1056/NEJMoa2002032Feb28

7. Zhang JJ et al (2020) Clinical characteristics of 140 patients infected by SARS-CoV-2 in Wuhan. China Allergy. https://doi. org/10.1111/all.14238

8. Li B et al (2020) Prevalence and impact of cardiovascular metabolic diseases on COVID-19in China. Clin Res Cardiol. https:// doi.org/10.1007/s00392-020-01626-9Mar11

9. Fadini GP, Morieri ML, Longato E, Avogaro A (2020) Prevalence and impact of diabetes among people infected with SARSCoV-2. J Endocrinol Invest. https://doi.org/10.1007/s4061 8-020-01236-2

10. Kruglikov IL, Scherer PE (2020) The role of adipocytes and adipocyte-like cells in the severity of COVID-19 infections. Obesity (Silver Spring). https://doi.org/10.1002/oby.22856

11. Wu Z et al (2019) Characteristics of and important lessons from the coronavirus disease 2019 (COVID-19) outbreak in China. Summary of a report of 72314 cases from the Chinese
Center for Disease Control and Prevention. JAMA. https://doi. org/10.1001/jama.2020.2648

12. Marik PE, Chen C (2016) The clinical characteristics and hospital and post-hospital survival of patients with the obesity hypoventilation syndrome: analysis of a large cohort. Obes Sci Pract 2(1):40-47

13. Gong MN, Bajwa EK, Thompson BT, Christiani DC (2010) Body mass index is associated with the development of acute respiratory distress syndrome. Thorax 65(1):44-50. https://doi. org/10.1136/thx.2009.117572

14. Simonnet A et al (2020) Intensive Care COVID-19 and Obesity study group. High prevalence of obesity in severe acute respiratory syndrome coronavirus-2 (SARS-CoV-2) requiring invasive mechanical ventilation. Obesity (Silver Spring). https ://doi.org/10.1002/oby.22831

15. Lighter $\mathrm{J}$ et al (2020) Obesity in patients younger than 60 years is a risk factor for Covid-19 hospital admission. Clin Infect Dis. https://doi.org/10.1093/cid/ciaa415

16. Sattar N, McInnes IB (2020) McMurray JJV obesity a risk factor for severe COVID-19 infection: multiple potential mechanisms. Circulation. https://doi.org/10.1161/CIRCULATIO NAHA.120.047659

17. Dhurandhar NV, Bailey D, Thomas D (2015) Interaction of obesity and infections. Obes Rev 16(12):1017-1029. https://doi. org/10.1111/obr. 12320

18. Green WD, Beck MA (2017) obesity impairs the adaptive immune response to Influenza virus. Ann Am Thorac Soc 14:S406-S409. https://doi.org/10.1513/AnnalsATS.20170 6-447AW

19. Hodgson K, Morris J, Bridson T, Govan B, Rush C, Ketheesan $\mathrm{N}$ (2015) Immunological mechanisms contributing to the double burden of diabetes and intracellular bacterial infections. Immunology 144(2):171-185. https://doi.org/10.1111/imm.12394

20. Wysocki J, Ye M, Soler MJ, Gurley SB, Xiao HD, Bernstein KE, Coffman TM, Chen S, Batlle D (2006) ACE and ACE2 activity in diabetic mice. Diabetes 55(7):2132-2139

21. Roca-Ho H, Riera M, Palau V, Pascual J, Soler MJ (2017) Characterization of ACE and ACE2 expression within different organs of the NOD mouse. Int J Mol Sci 18(3):E563. https ://doi.org/10.3390/ijms 18030563

22. Muniyappa R, Gubbi S (2020) COVID-19 pandemic, coronaviruses, and diabetes mellitus. Am J Physiol Endocrinol Metab 318(5):E736-E741. https://doi.org/10.1152/ajpendo.00124 .2020

23. Bornstein SR, Rubino F et al (2020) Practical recommendations for the management of diabetes in patients with COVID19. Lancet Diabetes Endocrinol. https://doi.org/10.1016/S2213 -8587(20)30152-2

24. Gupta R, Hussain A, Misra A (2020) Diabetes and COVID-19: evidence, current status and unanswered research questions. Eur J Clin Nutr. https://doi.org/10.1038/s41430-020-0652-1

25. Capoccia D, Coccia F, Guarisco G, Testa M, Rendina R, Abbatini F, Silecchia G, Leonetti F (2018) Long-term metabolic effects of laparoscopic sleeve gastrectomy. Obes Surg 28(8):2289-2296. https://doi.org/10.1007/s11695-018-3153-8

26. Capoccia D, Guida A, Coccia F, Guarisco G, Testa M, Leonetti F, Silecchia G (2020) Weight regain and diabetes evolution after sleeve gastrectomy: a cohort study with over 5 years of followup. Obes Surg 30(3):1046-1051. https://doi.org/10.1007/s1169 5-019-04350-0

27. Capoccia D, Silecchia G, Leonetti F et al (2015) Is type 2 diabetes really resolved after laparoscopic sleeve gastrectomy? Glucose variability studied by continuous glucose monitoring. J Diabetes Res 2015:674268. https://doi.org/10.1155/2015/67426 8 
28. Rubino F, Cohen RV, Mingrone G et al (2020) Bariatric and metabolic surgery during and after the COVID-19 pandemic: DSS recommendations for management of surgical candidates and postoperative patients and prioritisation of access to surgery. Lancet Diabetes Endocrinol. https://doi.org/10.1016/ S2213-8587(20)30157-1

29. https://aemmedi.it/wp-content/uploads/2020/03/PROTOCOLLO -TELEMEDICINA-COVID19-AMD_SID_SIE_28_03_20.pdf. Accessed 2020
Publisher's Note Springer Nature remains neutral with regard to jurisdictional claims in published maps and institutional affiliations. 